\title{
Development of Automated Sea-condition Monitoring System for Aquaculture in Indonesia
}

\author{
Masaaki Wada, ${ }^{1 *}$ Katsumori Hatanaka, ${ }^{2}$ and Mohamad Natsir ${ }^{3}$ \\ ${ }^{1}$ School of Systems Information Science, Future University Hakodate, \\ 116-2 Kamedanakano, Hakodate, Hokkaido 041-8655, Japan \\ ${ }^{2}$ Faculty of International Agriculture and Food Studies, Tokyo University of Agriculture, \\ 1-1-1 Sakuragaoka, Setagaya, Tokyo 156-8502, Japan \\ ${ }^{3}$ Center for Fisheries Research, Ministry of Marine Affairs and Fisheries, \\ Jalan Pasir Putih 2, Ancol Timur, Jakarta Utara 14430, Indonesia
}

(Received November 17, 2018; accepted December 26, 2018)

Keywords: monitoring, sea condition, aquaculture, mortality, optimization

In this paper, we report on a sea-condition monitoring system developed for establishing aquaculture technology in Indonesia. Increasing the aquaculture production in Indonesia is very important to ensure worldwide food security. However, the current aquaculture industry in Indonesia does not sufficiently accommodate changes in sea conditions and no established production technology exists. To solve this problem, we propose to optimize the aquaculture process by monitoring sea conditions. Our developed sea-condition monitoring system has an average power consumption of only $0.02 \mathrm{~W}$ and operates on a stand-alone basis with power obtained from solar panels throughout the year. The performance of the system was evaluated for a fish farm in northern Bali as the test site. We selected four types of sensor and monitored the seawater temperature, dissolved oxygen (DO) concentration, salinity, chlorophyll, and ocean current as parameters. During the evaluation period of $30 \mathrm{~d}$, no data were missing and the sea conditions were stably monitored. It was also found that the seawater circulation was good within the coral reef where the test site was located and that the seawater temperature, salinity, and DO concentration were suitable for the aquaculture of grouper. In future work, we will apply the developed system to plant farming and red-tide monitoring.

\section{Introduction}

According to Food and Agriculture Organization Statistics (FAOSTAT), the global production of fisheries and aquaculture has tended to increase and exceeded 20000 tons for the first time in 2016. ${ }^{(1)}$ Fisheries production has been saturated since reaching 9000 tons in 1994. In contrast, aquaculture production has increased and exceeded 10000 tons in 2014, overtaking fisheries production. As shown in Fig. 1, global aquaculture production has dominated in the developing countries in Asia. In 2016, the top three producers were China, Indonesia, and India. Among them, the aquaculture production in Indonesia accounts for $\sim 15 \%$ of the global 


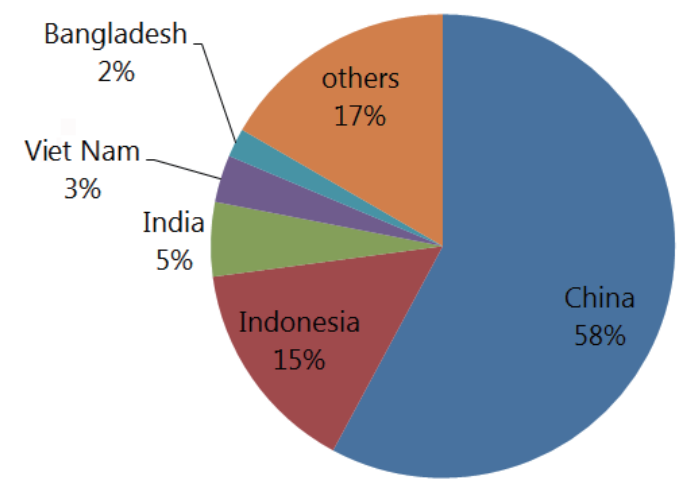

Fig. 1. (Color online) World aquaculture production in 2016.

aquaculture production. Towards ensuring global food security, "Eradicate extreme poverty and hunger" was set as Goal 1 of the Millennium Development Goals (MDGs) ${ }^{(2)}$ and was almost achieved by 2015. Subsequently, "Zero hunger" was set as Goal 2 of the Sustainable Development Goals (SDGs) ${ }^{(3)}$ in the 2030 Agenda. To achieve the SDGs by 2030, it is very important to increase aquaculture production in Indonesia, which has the world's second longest coastline.

However, global warming and urbanization have affected the sea conditions in aquaculture areas in Indonesia, resulting in, for example, higher mortality in fish farming [Fig. 2(a)] and greater occurrence of plant diseases in plant farming [Fig. 2(b)] because no aquaculture production technology has been established. To increase aquaculture production, the establishment of aquaculture technology is required in addition to the expansion of aquaculture areas. We believe that the relationship between the sea conditions and mortality and disease can be evaluated by monitoring sea conditions and logging the aquaculture process. In the future, artificial intelligence (AI)-based optimization of the aquaculture process will become possible by generating and analyzing big data. In this paper, we report on a sea-condition monitoring system developed for establishing aquaculture technology in Indonesia.

\section{Development of Sea-condition Monitoring System}

The sea-condition monitoring system is designed to be installed in fish and plant farming facilities and to automatically monitor sea conditions. The main requirements of the system are given below.

(Requirement 1) The system can operate on a battery for a long time.

(Requirement 2) Monitoring data can be checked remotely.

(Requirement 3) Multiple commercial sensors can be connected to the system.

In addition, low initial and running costs are essential, which will be considered in future work. Previously, we developed a sea-condition monitoring system for establishing aquaculture technology for Mizuhopecten yessoensis in Japan and put the system into practice. ${ }^{(4,5)}$ This system satisfies Requirements 1 and 3 but does not satisfy Requirement 2 because it can 


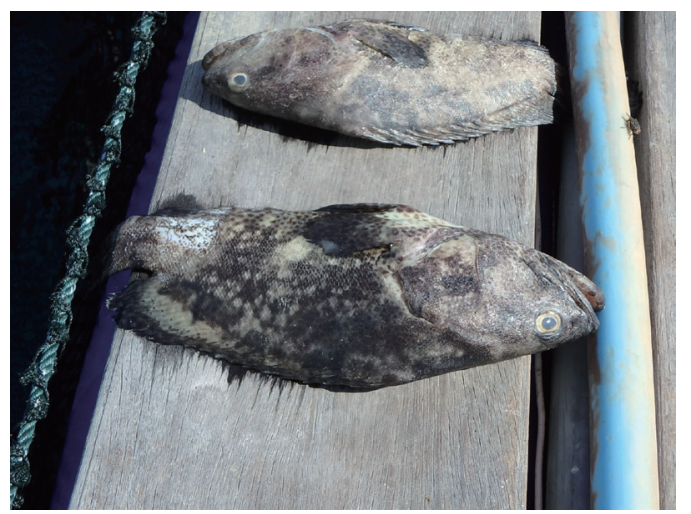

(a)

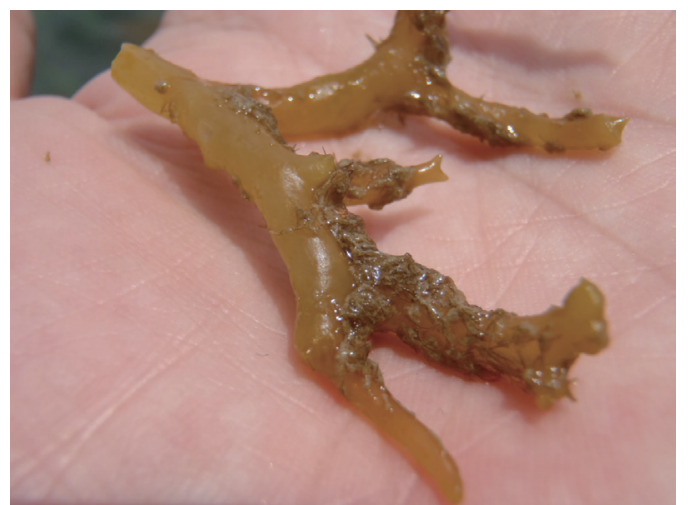

(b)

Fig. 2. (Color online) (a) Mortality of fish and (b) disease of plants.

only transmit monitoring data via the network of third-generation (3G) telecommunications technology provided by carrier companies in Japan. Moreover, the $3 \mathrm{G}$ network may be unavailable in some of the aquaculture areas in Indonesia. To address these problems, we developed a new sea-condition monitoring system.

\subsection{Specifications of the developed sea-condition monitoring system}

Figures 3(a) and 3(b) show the printed circuit board (PCB) and the body of the developed system, respectively. Tables 1 and 2 show their respective specifications. To meet Requirement 1, a CPU with a real-time clock (RTC) was selected. To meet Requirement 2, a satellite communication module was used for a transceiver. To meet Requirement 3, a multidrop interface was adopted. The body has a solar panel so that it can be powered on a stand-alone basis, as required for the geographical conditions of Indonesia, which is located at a low latitude, and the installation conditions of the system. The body houses the PCB, lead-acid battery, and a charge controller. A satellite communication antenna was positioned on the upper part of the body.

\subsection{Selection of sensors}

The sea-condition monitoring system can be connected to up to four commercial sensors with an RS-485 interface. We selected four types of sensor: a sensor for monitoring the dissolved oxygen (DO) concentration, an important factor in fish farming; a sensor for monitoring salinity, an important factor in plant farming; a sensor for monitoring chlorophyll as an index of red tides; and a sensor for monitoring the ocean current as an index of the exchange of seawater. Table 3 shows the specifications of the sensors. Among them, ARO2CAD, ACTW-CAD, and ACLW2-CAD have a wiper and are suitable for long-term monitoring. Moreover, all the sensors can monitor the seawater temperature. 


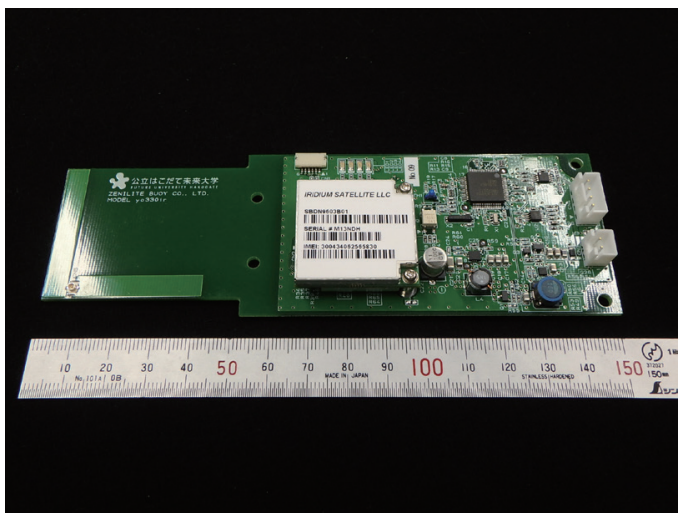

(a)

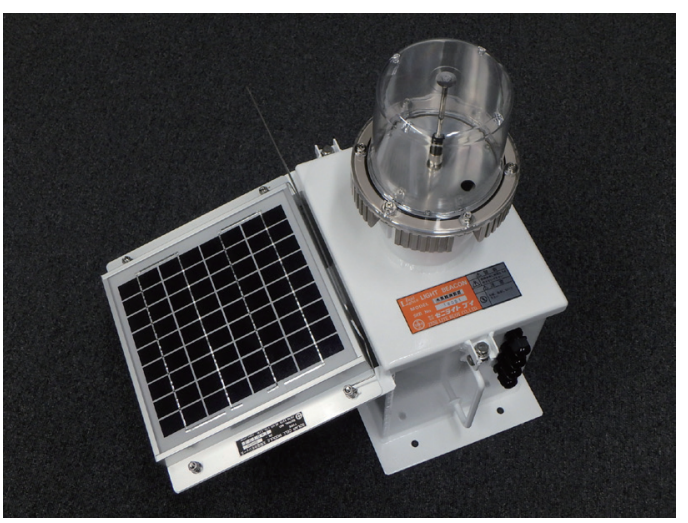

(b)

Fig. 3. (Color online) (a) PCB and (b) body.

Table 1

Specifications of PCB.

\begin{tabular}{lc}
\hline CPU & H8S/2212 (Renesas) \\
\hline Flash ROM/RAM & $128 \mathrm{kbyte} / 12 \mathrm{kbyte}$ \\
\hline Main clock/Sub clock & $14.746 \mathrm{MHz} / 32.768 \mathrm{kHz}$ \\
\hline Other functions & RTC \\
\hline Interface & RS-485 half-duplex \\
\hline Transceiver & Iridium 9603 (Iridium) \\
\hline Operation voltage & 3.6 to $14.0 \mathrm{VDC}$ \\
\hline Standby current & $0.6 \mathrm{~mA}$ \\
\hline Operating current & 24 (typical) $/ 100(\mathrm{maximum}) \mathrm{mA}$ \\
\hline Size & $150 \times 50 \mathrm{~mm}^{2}$ \\
\hline Weight & $40 \mathrm{~g}$ \\
\hline
\end{tabular}

Table 2

Specifications of body.

\begin{tabular}{lc}
\hline Material & Aluminum alloy \\
\hline Antenna & $1 / 2$-wave whip antenna \\
\hline Solar panel & $17.2 \mathrm{~V} / 5.3 \mathrm{~W}$ \\
\hline Controller & SVC-R2 $($ Zeni Lite $)$ \\
\hline Battery & Lead-acid battery $12 \mathrm{~V} / 8 \mathrm{Ah}$ \\
\hline Size & $350 \times 475 \times 501 \mathrm{~mm}^{3}(\mathrm{H})$ \\
\hline Weight & $13 \mathrm{~kg}$ \\
\hline
\end{tabular}

Table 3

Specifications of sensors.

\begin{tabular}{lcc}
\hline Model & Parameter & Range (Accuracy) \\
\hline \multirow{2}{*}{ ACLW2-CAD (JFE Advantech) } & Chlorophyll & 0 to $400 \mathrm{ppb}( \pm 1 \% \mathrm{FS})$ \\
& Seawater temperature & -3 to $45^{\circ} \mathrm{C}\left( \pm 0.02{ }^{\circ} \mathrm{C}\right)$ \\
\hline \multirow{2}{*}{ AEM-CAD (JFE Advantech) } & Velocity & 0 to $\pm 500 \mathrm{~cm} / \mathrm{s}( \pm 1 \mathrm{~cm} / \mathrm{s})$ \\
& Direction & 0 to $360^{\circ}\left( \pm 2^{\circ}\right)$ \\
\multirow{2}{*}{ ARO2-CAD (JFE Advantech) } & Seawater temperature & -3 to $45^{\circ} \mathrm{C}\left( \pm 0.02{ }^{\circ} \mathrm{C}\right)$ \\
\hline \multirow{2}{*}{ ACTW-CAD (JFE Advantech) } & DO & 0 to $200 \%( \pm 2 \%)$ \\
& Seawater temperature & -3 to $45^{\circ} \mathrm{C}\left( \pm 0.02{ }^{\circ} \mathrm{C}\right)$ \\
\hline
\end{tabular}

\subsection{Structure of firmware}

Firmware was developed from scratch and installed in the system. Figure 4 shows flowcharts of the firmware. The firmware consists of three tasks and a timer. Task 1 is the main task and controls Tasks 2 and 3 and Timer 1 . Task 1 is activated when the system shifts 

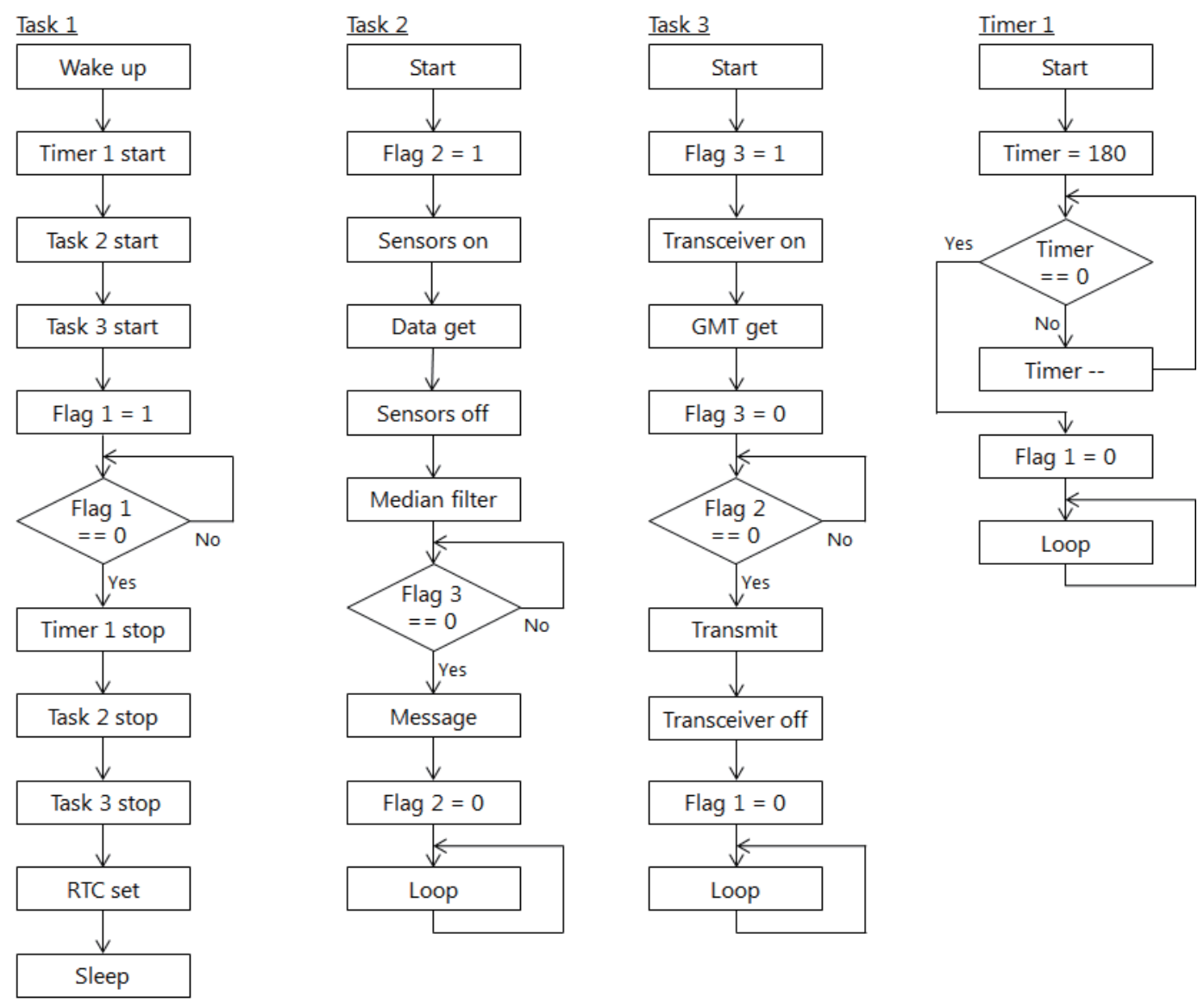

Fig. 4. Flow charts of firmware.

from the sleep mode to the operation mode upon the interruption of the RTC. The operation mode returns to the sleep mode, triggered by the completion of data transmission by Task 3 or the timeout of Timer 1.

Task 2 controls the sensors. After the four sensors are turned on and the lenses are cleaned by wipers activated by command, monitoring data are obtained from the sensors. Each sensor has a unique identification (ID) number. Monitoring data are obtained three times every second and the median yielded by a median filter is adopted. The time required to obtain the median from the start of Task 2 and the current were measured. For five measurements, the average time taken was $26 \mathrm{~s}$, the average current was $167 \mathrm{~mA}$, and the maximum current was $251 \mathrm{~mA}$. A message including the date, time, and monitoring data is created after Task 3 has obtained Greenwich Mean Time (GMT).

Task 3 controls the transceiver. After the transceiver is turned on, the system time received from a satellite by command is converted into GMT. Task 3 stores a message created by Task 2 in a buffer and commands the start of its transmission. The transmission of messages is controlled by the transceiver. Because Iridium Short Burst Data (SBD) ${ }^{(6)}$ is a data communication service using a low-orbit satellite network, the time required to transmit a message depends on the location of the satellites and other conditions. When the transmission 
of the message is successful, the returned value is 1 . When it fails, the returned value is 2 . When the returned value is 2 , Task 3 clears the buffer by command, again stores the message in the buffer, and commands the transmission of the message. The time required to obtain GMT from the start of Task 2 was measured. The average time of five measurements was $10 \mathrm{~s}$. The current required to transmit a message was similarly measured five times. The maximum current was $103 \mathrm{~mA}$.

Timer 1 controls the operation time. When a deadlock occurs because of some problem with the sensors and the transceiver, controlled by Tasks 2 and 3, respectively, Task 1 forcibly stops Tasks 2 and 3 upon a timeout and the system shifts from the operation mode to the sleep mode. The timeout period is set to $180 \mathrm{~s}$.

\section{Experiments at Test Site}

Figure 5 shows a simplified map of the area around a fish farm in northern Bali, which was selected as the test site, and the developed system was installed on September 14, 2018 (Fig. 6).

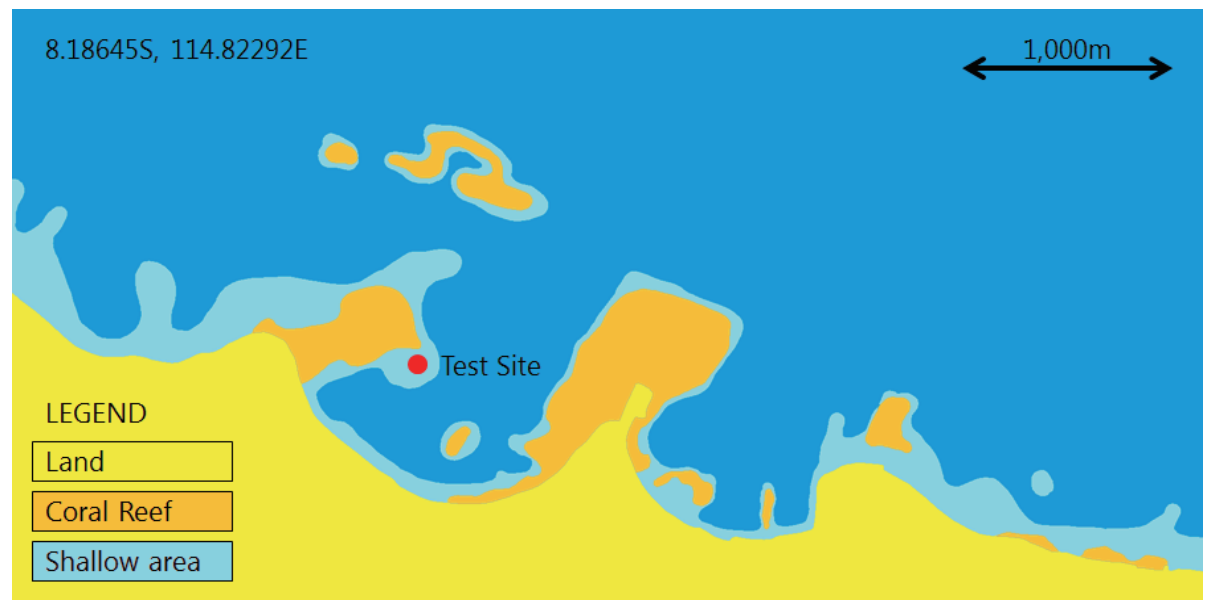

Fig. 5. (Color online) Geography around the test site.

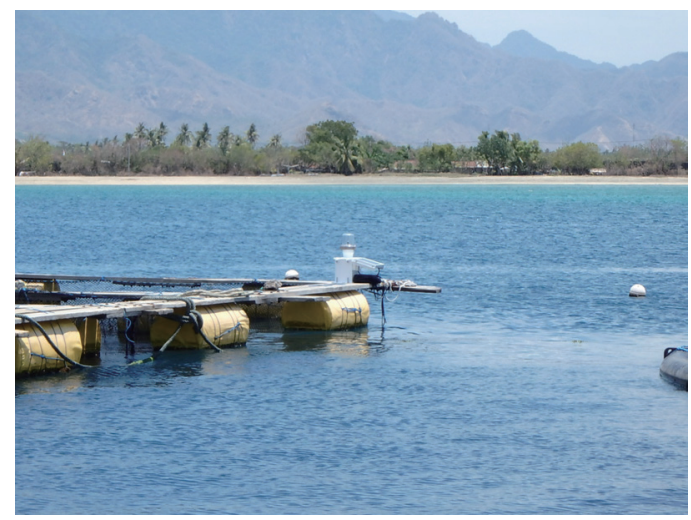

Fig. 6. (Color online) Equipment on the cage. 
At this test site, grouper and Japanese barramundi (Lates japonicus) were being cultured. The water depth at the test site is $\sim 20 \mathrm{~m}$, and the bottom of the cage net is positioned $\sim 5 \mathrm{~m}$ below sea level. The sensor for monitoring the ocean current [Fig. 7(a)] was positioned in the middle layer, that is, $\sim 10 \mathrm{~m}$ below sea level, whereas the other sensors [Fig. 7(b)] were positioned $\sim 4 \mathrm{~m}$ below sea level, where the grouper and Japanese barramundi live. The four sensors were hung using ropes and the sea conditions were monitored every hour and half-hour. As reported in the following subsection, we evaluated the monitoring data obtained over $30 \mathrm{~d}$ between September 16 and October 15, 2018.

\subsection{Evaluation of satellite communication}

Messages including monitoring data are transmitted by the Iridium SBD service. The messages transmitted from the sea-condition monitoring system are relayed through the satellite network, delivered to the global station in the US, and then sent as attachments via the Internet to a registered email address. The subject line of such emails includes the International Mobile Equipment Identifier (IMEI), which enables us to identify the sea-condition monitoring system. The system monitors the DO concentration, salinity, chlorophyll, and ocean current as the sea conditions on the hour and half-hour. On the hour, a message including all parameters is created. On the half-hour, however, a message including only the ocean current, which is considered to change more with time than the other parameters, is created, because the SBD service charges pay-per-use.

During the evaluation period of $30 \mathrm{~d}$, there were 1440 half-hour intervals and no data were missing. The delay time was evaluated using the time stamp included in the header of the emails. Considering that the time required for monitoring was $26 \mathrm{~s}$, as explained in Sect. 2.3, the average delay time was $15 \mathrm{~s}$, the minimum delay time was $6 \mathrm{~s}$, and the maximum delay time was $656 \mathrm{~s}$. Delays of less than $30 \mathrm{~s}$ accounted for $94.7 \%$ of transmissions and those of $90 \mathrm{~s}$ or more accounted for $0.8 \%$ of transmissions.

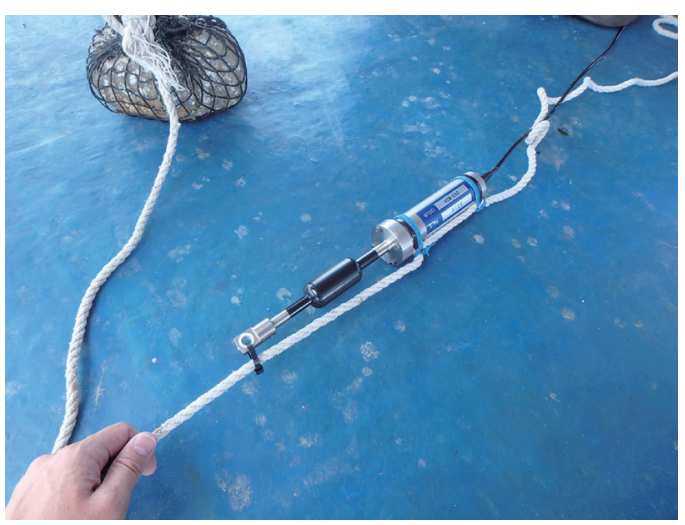

(a)

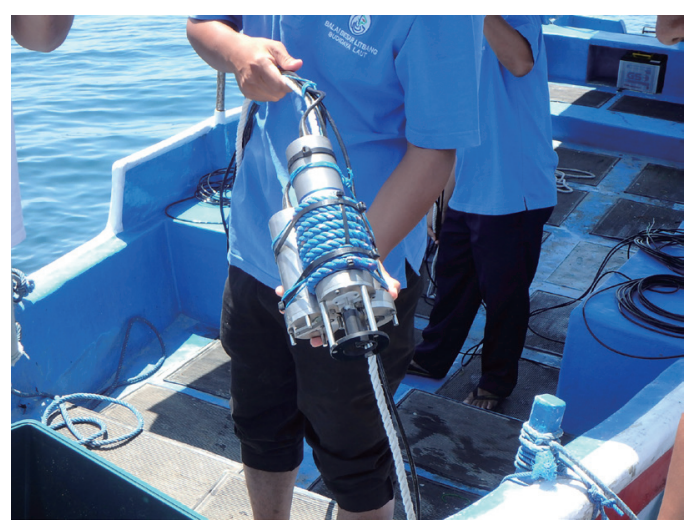

(b)

Fig. 7. (Color online) (a) AEM-CAD and (b) ARO2-CAD, ACTW-CAD, and ACLW2-CAD. 


\subsection{Evaluation of current consumption}

Current consumption was calculated from the delay time. It was assumed that there is a delay time of $15 \mathrm{~s}$ from the command for the start of transmission of a message to the successful transmission and that the maximum current is consumed in the last $1 \mathrm{~s}$. The operation time was $41 \mathrm{~s}$, and currents of 167, 24, and $103 \mathrm{~mA}$ were consumed in the first $26 \mathrm{~s}$, the following $14 \mathrm{~s}$, and the last $1 \mathrm{~s}$, respectively. The average current consumption in the operation mode was 116.6 mA. The average current consumption in the sleep mode was $0.6 \mathrm{~mA}$. Therefore, the average current consumption and power consumption of the entire system were $1.62 \mathrm{~mA}$ and $\sim 0.02 \mathrm{~W}$, respectively. Assuming that power is supplied by eight size-D alkaline batteries, the system is expected to operate continuously for $\sim 257 \mathrm{~d}$. Figure 8 shows the daily time variation of the voltage for the lead-acid battery. The battery is charged during the day and discharged at night.

In addition, the voltage reaches a peak after sunrise, at noon, and before sunset. During the day, charge and discharge of the battery are repeated upon the detection of full charge by the charge controller. Thus, we confirmed that the system operates on a stand-alone basis powered by the solar panel throughout the year.

\subsection{Evaluation of aquaculture area}

The manual for the aquaculture of grouper $^{(7)}$ specifies recommended values of the seawater temperature $\left(25-32{ }^{\circ} \mathrm{C}\right)$, salinity (20-32 PSU), and DO concentration $(4-8 \mathrm{mg} / \mathrm{L})$. Table 4 shows the minimum, mean, and maximum of these parameters obtained from monitoring during the evaluation period. Salinity was calculated using an equation involving electric conductivity and seawater temperature ${ }^{(8)}$ and is given in the practical salinity unit (PSU). The DO concentration is given in $\mathrm{mg} / \mathrm{L}$ and is calculated using an equation involving seawater temperature, salinity, and DO concentration in $\%{ }^{(9)}$

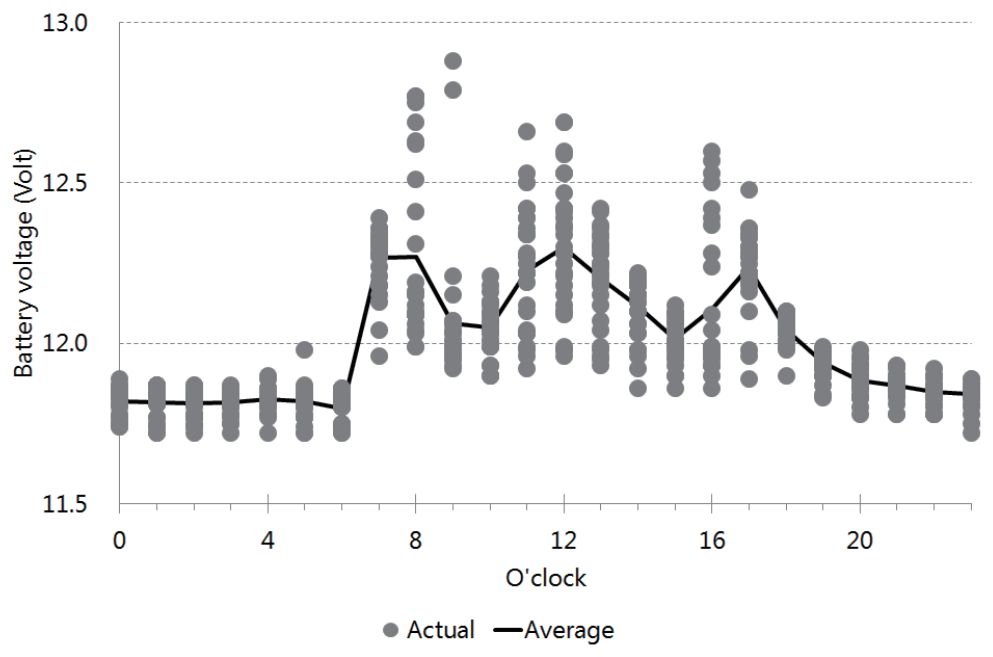

Fig. 8. Time variation of the battery voltage. 
Figure 9 shows the time variation of the seawater temperature at depths of 4 and $10 \mathrm{~m}$ below sea level. The change in the seawater temperature at $4 \mathrm{~m}$ was larger than that at $10 \mathrm{~m}$. When the frequency characteristics were confirmed by a fast Fourier transform (FFT), the seawater temperature at $10 \mathrm{~m}$ showed a periodicity of $24 \mathrm{~h}$, whereas that at $4 \mathrm{~m}$ showed periodicities of 12 and $24 \mathrm{~h}$.

Figure 10 shows time variations of the salinity and DO concentration. We confirmed that the seawater temperature and DO concentration were maintained in the ranges of the recommended values and that the salinity was slightly higher than the recommended value, at least during the evaluation period.

Table 4

Statistics of each parameter.

\begin{tabular}{lccc}
\hline & Minimum & Average & Maximum \\
\hline Seawater temperature: $4 \mathrm{~m}\left({ }^{\circ} \mathrm{C}\right)$ & 27.8 & 28.8 & 30.3 \\
Seawater temperature: $10 \mathrm{~m}\left({ }^{\circ} \mathrm{C}\right)$ & 27.6 & 28.4 & 29.3 \\
Salinity (PSU) & 25.1 & 34.1 & 34.2 \\
DO $(\mathrm{mg} / \mathrm{L})$ & 5.1 & 6.3 & 6.9 \\
\hline
\end{tabular}

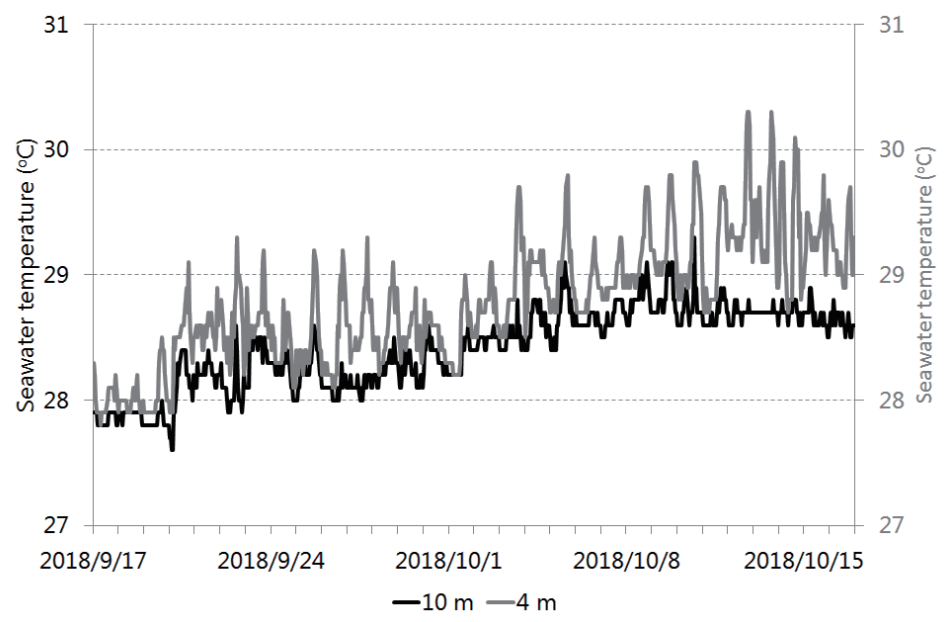

Fig. 9. Time variation of seawater temperature.

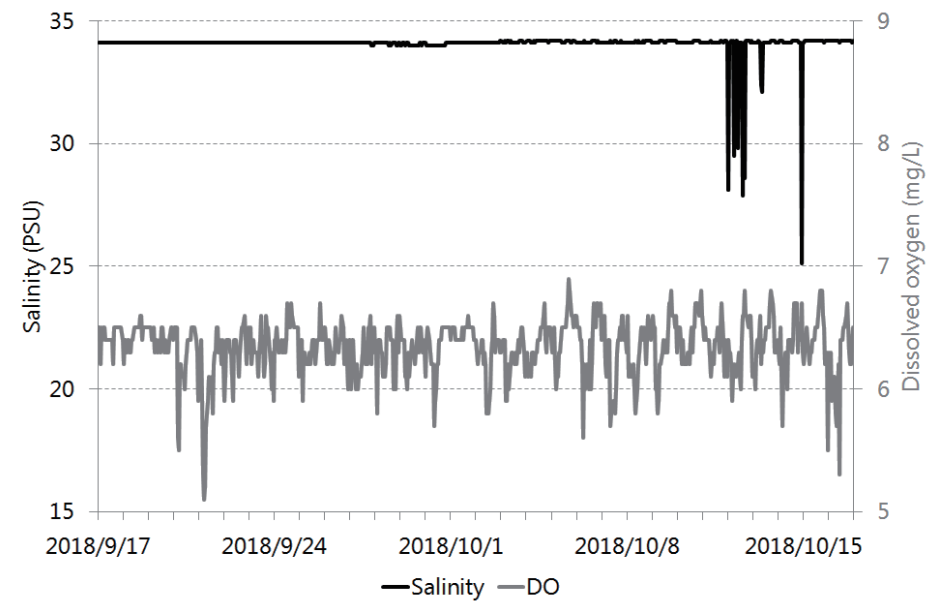

Fig. 10. Time variations of salinity and DO. 


\subsection{Evaluation of ocean current}

Figure 11 shows the time variation of the ocean current velocity. During the evaluation period, a full moon occurred on September 25 and a new moon occurred on October 9. When the frequency characteristics were confirmed by a FFT, periodicities of 6,12 , and $24 \mathrm{~h}$ were observed.

Figure 12 shows the tendency of the ocean current. The integrated values of the ocean current velocity during the evaluation period in 16 directions are shown in the unit of meter. There were no significant differences between the graphs obtained using only the data obtained on the hour and those obtained on both the hour and the half-hour. In addition, east-northeast (ENE) was found to be the dominant direction of the ocean current flow during the evaluation period. It is suggested that seawater circulates clockwise within the coral reef where the test site is located.

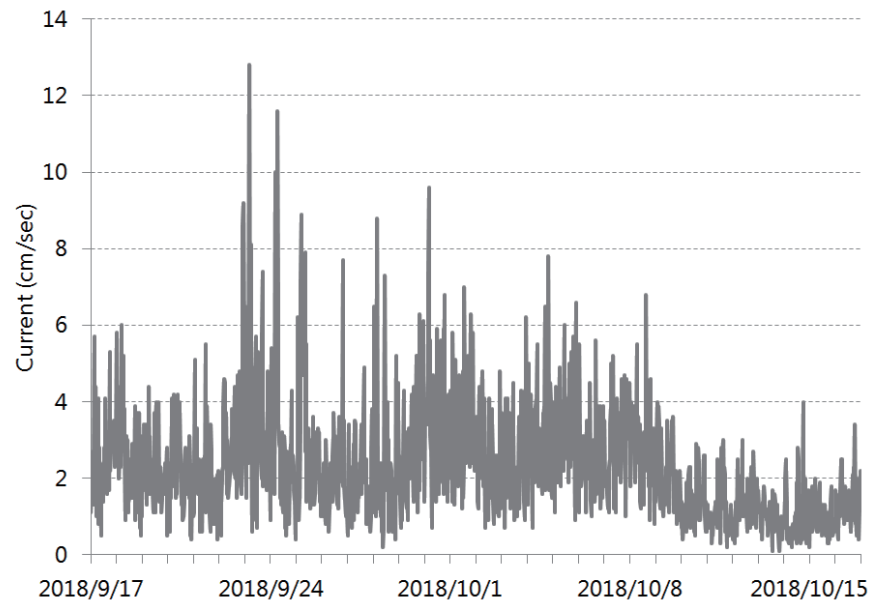

Fig. 11. Time variation of current velocity.

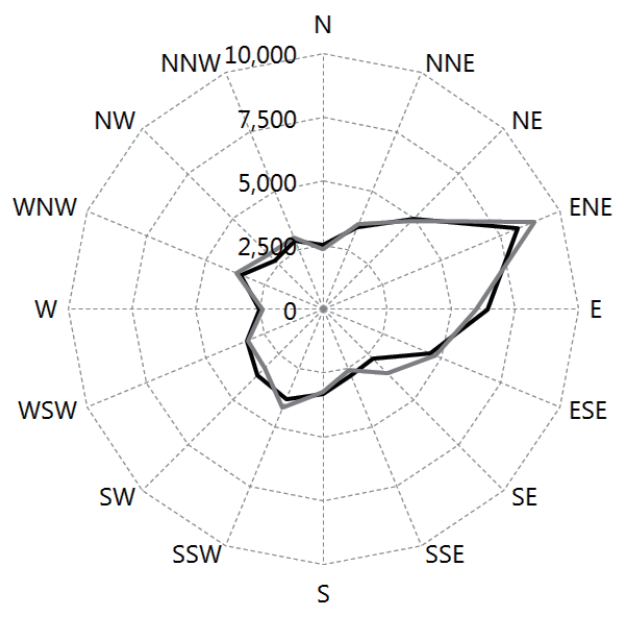

-30 minutes interval -60 minutes interval

Fig. 12. Tendency of current direction. 


\section{Conclusions}

In this paper, we reported on a sea-condition monitoring system developed for establishing aquaculture technology in Indonesia and the evaluation results of the monitoring data obtained at the test site over $30 \mathrm{~d}$. The system stably monitored sea conditions and exhibited satisfactory reliability. At the test site in northern Bali, the salinity was slightly higher than the recommended value, but the seawater temperature was appropriate and the DO concentration was stable because of good seawater circulation; thus, the test site is considered to be suitable for fish farming. Monitoring of the sea conditions is still continuing at the test site. In addition, we are developing a digital logbook for logging the farming process and will evaluate the relationship between sea conditions and fish mortality.

We will install the sea-condition monitoring system at a new test site for plant farming in southern Lombok. Moreover, we also plan to install the system in southern Sumatra to monitor red tides. For this test site, monitoring of the climatic conditions, such as the wind and rainfall, in addition to sea conditions is necessary. To meet this requirement, firmware will be updated to enable connection to a commercial weather station.

The collection of big data is essential for optimizing the AI-based aquaculture process. Hence, we must install the developed system at many test sites and also devise a secondgeneration sea-condition monitoring system with low initial and running costs. We will start the operation of 10 sea-condition monitoring systems by the end of December 2019. After establishing aquaculture technology in Indonesia, we plan to expand to other developing countries in Asia such as India and Viet Nam in the future. We believe that this will lead to the achievement of the SDGs by 2030.

\section{Acknowledgments}

This work was supported by Science and Technology Research Partnership for Sustainable Development (SATREPS), Japan Science and Technology Agency (JST), and Japan International Cooperation Agency (JICA) program for research projects targeting global issues and involving partnerships between researchers in Japan and developing countries.

\section{References}

1 FAOSTAT: http://www.fao.org/fishery (accessed October 2018).

2 MDGs: http://www.undp.org/content/undp/en/home/sdgoverview/mdg_goals.html (accessed December 2018).

3 SDGs: http://www.undp.org/content/undp/en/home/sustainable-development-goals.html (accessed December 2018).

4 M. Wada, K. Hatanaka, and M. Toda: J. Commun. 3 (2008) 2.

5 M. Wada and K. Hatanaka: Proc. OCEANS 2011 MTS/IEEE (2000).

6 Iridium: https://www.iridium.com/services/iridium-sbd (accessed October 2018).

7 S. Ismi, T. Sutarmat, N. A. Giri, M. A. Rimmer, R. M. J. Knuckey, A. C. Berding, and K. Sugama: Nursery management of grouper: a best-practice manual (Australian Centre for International Agricultural Research, 2012). https://www.aciar.gov.au/node/10826

8 JFE Advantech: http://ocean.jfe-advantech.co.jp/sensor/img/salinity.pdf (accessed October 2018).

9 JFE Advantech: http://ocean.jfe-advantech.co.jp/sensor/img/do.pdf (accessed October 2018). 


\section{About the Authors}

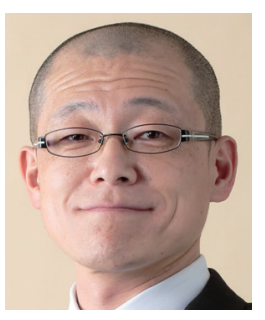

Masaaki Wada received his B.S. degree from Hokkaido University, Japan, in 1993 and his Ph.D. degree from the Graduate School of Fisheries Sciences, Hokkaido University, Japan, in 2004. From 1993 to 2004, he was an engineer at Towa Denki Seisakusho, Japan. In 2005, he moved to Future University Hakodate, Japan. From 2005 to 2011, he was an associate professor, and since 2012, he has been a professor. His research interests are in capture and culture fisheries and information technologies such as internet of things, big data, and artificial intelligence. (wada@fun.ac.jp)

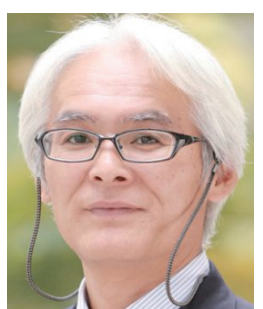

Katsumori Hatanaka received his B.S., M.S., and Ph.D. degrees from Chuo University, Japan, in 1985, 1991, and 1993, respectively. From 1993 to 1998, he was an assistant professor at Nihon University, Japan. From 1998 to 2006, he was an associate professor at Tokai University, Japan. In 2006, he moved to the Tokyo University of Agriculture, and since 2012, he has been a professor. His research interests are in numerical analysis and applications for agricultural and fishery industries. (k3hatana@nodai.ac.jp)

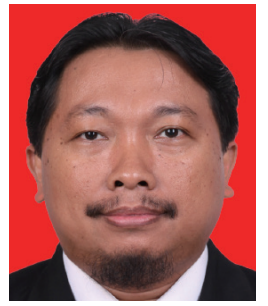

Mohamad Natsir received his B.S. degree from Bogor Agricultural University, Indonesia, in 2001 and his M.S. degree from Bogor Agricultural University in 2010. From 2002 to 2010, he was a research associate in the Research Institute for Marine Fisheries (RIMF), Indonesia. Since 2010, he has been a full-time researcher at RIMF and moved to the Center for Fisheries Research (CFR) in 2012. His research interests are in fisheries acoustics, capture fisheries, and fisheries management. (natsir@kkp.gp.id) 